\title{
VIABILIDADE DO USO DE NUCLEAÇÃO NO AUXÍLIO DA REGULARIZAÇÃO AMBIENTAL DAS ATIVIDADES DE EXTRAÇÃO DE ARGILA EM REGIÃO DE INTENSA ALTERAÇÃO DA PAISAGEM
}

\author{
Cássia Maria Gama LEMOS $^{1}$ \& Gilda Carneiro FERREIRA ${ }^{2}$
}

(1) Centro de Ciência do Sistema Terrestre do Instituto Nacional de Pesquisas Espaciais. Avenida dos Astronautas, 1758 - Jardim da Granja. CEP: 12227-010. São José dos Campos - São Paulo. Endereço Eletrônico: cassia.ambientalunifei@ yahoo.com.br.

(2) Departamento de Geologia Aplicada do Instituto de Geociências e Ciências Exatas da Universidade Estadual Paulista/Campus de Rio Claro. Avenida 24-A, 1515 - Bela Vista. CEP 13506-900. Rio Claro, SP. Endereço eletrônico: gilda@ rc.unesp.br.

\author{
Introdução \\ Área de estudo \\ Materiais e Métodos \\ Resultados \\ Discussão \\ Conclusão \\ Agradecimentos \\ Referências bibliográficas
}

\begin{abstract}
RESUMO - Próximo de completar uma década de atividades, o projeto "Apoio técnico às atividades de extração de matéria-prima executadas pela indústria oleira da região de Rio Claro" realizou, recentemente, o estudo da viabilidade do uso da nucleação como auxílio na elaboração do projeto de recuperação de uma área de preservação permanente de nascente. O resultado obtido durante esta etapa do projeto é o objetivo deste artigo, para tal será apresentada a proposta de recuperação desta área degradada que considerou etapas de caracterização da área, de monitoramento da regeneração natural, de implantação da técnica de transposição de solo e serrapilheira e de monitoramento desta técnica. Durante a caracterização, foram analisados os pré-requisitos à implantação das técnicas de nucleação. Depois de confirmada a viabilidade da implantação das técnicas de nucleação, foi escolhida a técnica de transposição de solo e serrapilheira para ser implantada e monitorada. O monitoramento ocorreu por cinco meses, após este período, foi possível observar a regeneração natural ocorrendo na área de preservação da nascente em estudo, além de indicativos de intensa atividade biológica na parcela transplantada.
\end{abstract}

Palavras- chave: Mineração, Olaria, Meio ambiente, Área degradada

\begin{abstract}
Next to complete one decade of activity, the project " "Apoio técnico às atividades de extração de matéria-prima executadas pela indústria oleira da região de Rio Claro", did, recently, the study of the viability of using nucleation as assistance in the elaboration of the rehabilitation project of the permanent preservation area of the water spring. The result of this part of the project is the aim of this article, for this will be presented the proposed of rehabilitation of degraded area considered steps of characterization of the area, natural regeneration monitoring, implementation of the technique and monitoring of this technique. During characterization, the pre-requisites for the implementation of nucleation techniques were analyzed. After confirmed the viability of the implementation of nucleation techniques, it was chosen soil transposition technique to be implemented and to be monitored. The monitoring occurred by five months, after this period, the natural regeneration was observed occurring in the preservation area. And indicative of intense biological activity in the transplanted nucleus was observed too.
\end{abstract}

Keywords: Mining, Pottery, Environment, Degraded area

\section{INTRODUÇÃO}

Devido à disponibilidade de argila, há várias décadas, a região de Rio Claro apresenta grande número fábricas produzindo cerâmicas de revestimento e vermelha. Entre estas fábricas, estão cerca de 50 olarias de pequeno porte (Daitx \& Ferreira, 2006). Segundo Scalco et al. (2014), no início das atividades de extração da matéria-prima nesta região, a argila era extraída nas proximidades da olaria, preferencialmente na várzea de rios. As técnicas utilizadas eram rudimentares, manuais e empíricas, baseadas no conhecimento do produtor mais experiente. As mesmas autoras descrevem que ao final da década de 80 e início de 90 , ainda utilizando de técnicas rudimentares sem qualquer orientação técnica, a extração manual foi substituída pela extração utilizando equipamentos motorizados. Hoje, muitas das pequenas olarias, localizadas na região de Rio Claro, tiveram suas atividades de extração de argila paralisadas por ordem do Órgão Ambiental responsável pelo licenciamento deste tipo de atividade. Assim que licenciada, a atividade de extração de argila seguirá orientações técnicas descritas nos planos de lavras elaborados segundo as particularidades de cada área a ser lavrada (Ferreira, 2007; Ferreira et al., 2012).

Frente à necessidade de regularizar seus empreendimentos de extração mineral no tocante do seu licenciamento mineral e ambiental, os pequenos produtores se organizaram e criaram uma associação 
conhecida como Associação das Cerâmicas Vermelha de Rio Claro e Região (ASCER). E através desta, os produtores de cerâmica da região de Rio Claro solicitaram suporte técnico à Universidade Estadual Júlio de Mesquita Filho - Campus Rio Claro, para que esta os orientasse na obtenção das licenças mineral e ambiental das olarias (Daitx \& Ferreira, 2006). Sendo assim, desde 2007 pesquisadores do Laboratório de Quantificação e Análise de Dados Geológicos do Departamento de Geologia Aplicada do Instituto de Geociências e Ciências Exatas da Universidade Estadual Paulista Júlio de Mesquita Filho (LQUAD/DGA/ IGCE/UNESP) auxiliam a ASCER na regularização da sua atividade de extração mineral para a produção de cerâmica vermelha (Ferreira et al., 2012).

De forma a contribuir com a regularização mineral e ambiental das atividades dos mineradores de pequenas áreas de extração de argila, desde o início desta parceria, estes pesquisadores já orientaram os oleiros no que se refere à situação legal minerária e ambiental das atuais áreas de extração e das atividades necessárias à sua regularização; montaram os processos administrativos para protocolo no Departamento Nacional de Produção Mineral (DNPM), visando à obtenção das autorizações minerais; elaboraram os Relatórios Finais de Pesquisa e os projetos de extração e/ou dos Planos de Aproveitamento Econômico das jazidas de argila em cada área titulada; amostraram os materiais de interesse dos oleiros e quantificou os volumes desses materiais presentes nas áreas tituladas, na escala e precisão condizentes com a natureza de cada título minerário; executaram ensaios físicos para caracterizar as propriedades cerâmicas dos materiais argilosos em uso nas olarias; realizaram o diagnóstico ambiental e a avaliação dos impactos ambientais (Ferreira et al., 2015). E atualmente, auxiliaram na elaboração do Projeto de Recuperação de Área Degradada (PRAD) de uma Área de Preservação Permanente.

O objetivo deste artigo é apresentar, em especial, a recente etapa desta interação entre LQUAD/DGA/IGCE/UNESP e oleiros da ASCER. Etapa esta que buscou analisar a viabilidade de recuperação de uma Área de Preservação Permanente (APP) degradada utilizando as técnicas de nucleação, como subsídio na atividade de licenciamento ambiental de uma pequena propriedade rural que apresenta atividade de extração de argila em processo de licenciamento. Os PRADs são exigidos tanto pelo DNPM através das Normas Reguladoras de Mineração $\mathrm{n}^{\circ} 20$ e $\mathrm{n}^{\circ} 21$ da Portaria $n^{\circ} 237$ de 18 de outubro de 2001, quanto pela Companhia Ambiental do Estado de São Paulo (CETESB), órgão ambiental licenciador e fiscalizador das questões ambientais das atividades minerária no estado de São Paulo (BRASIL, 2001; SÃO PAULO, 2014a).

\section{Área de estudo}

Nesta etapa, a área de estudo é uma APP de nascente (Figura 1) de um dos afluentes do Ribeirão Jacutinga, posicionada no município de Corumbataí, em propriedade denominada Sítio São Sebastião, Bairro Jacutinga. Esta APP está inserida em uma Área de Preservação Ambiental (SÃO PAULO, 1983), sendo as coordenadas do centro desta APP de $23 \mathrm{~K}$ $7528,10 \mathrm{~m}$ e $228,12 \mathrm{~m}$ (Coordenadas UTM Universal Transversa de Mercator) (Lemos, 2015). Hoje, esta atividade na propriedade está paralisada por ordem da CETESB até que seja finalizado o atual processo de licenciamento ambiental. Assim que liberada a licença ambiental, a atividade será realizada segundo o plano de lavra, em que o método de lavra a ser adotado será o de céu aberto, em tiras (uma única bancada de $2,5 \mathrm{~m}$ de altura), com extensão prevista de até 100 metros, no qual a lavra irá desenvolver-se em direção paralela à maior dimensão do corpo (Ferreira, 2007).

A Bacia do Ribeirão Jacutinga, assim como todo o interior do estado de São Paulo, apresenta grande fragmentação vegetal resultado de atividades antrópicas, gerando remanescentes florestais em diferentes condições ecológicas (Scalco \& Ferreira, 2013). Os fragmentos florestais em melhor estado de preservação encontram-se próximos à rede hidrográfica e em terrenos mais declivosos (Valente, 2001), sendo estes protegidos pela Lei $\mathrm{n}^{\mathrm{o}}$ 12.651, de 25 de maio de 2012 (BRASIL, 2012). Na Bacia do Ribeirão Jacutinga, as matas ciliares estão normalmente reduzidas a uma faixa estreita, cujo entorno é ocupado por lavouras ou pastagens. Mesmo sendo pequenos 
remanescentes florestais, estes cumprem funções relevantes ao longo da paisagem (Valente, 2001; Scalco, 2012). Além dos impactos ambientais atuais, a Bacia ainda sofre com as consequências dos impactos ambientais gerados no passado, impactos estes oriundos da exploração de argila utilizando técnicas incorretas, que desrespeitaram as características ambientais no que tange as potencialidades, limitações e fragilidades do manto intemperizado da Formação Corumbataí. A retirada da cobertura vegetal, no passado, aumentou os processos erosivos que resultam, hoje, no assoreamento de corpos hídricos, perda de solo e diminuição da capacidade de infiltração nas vertentes (Scalco \& Ferreira, 2013).

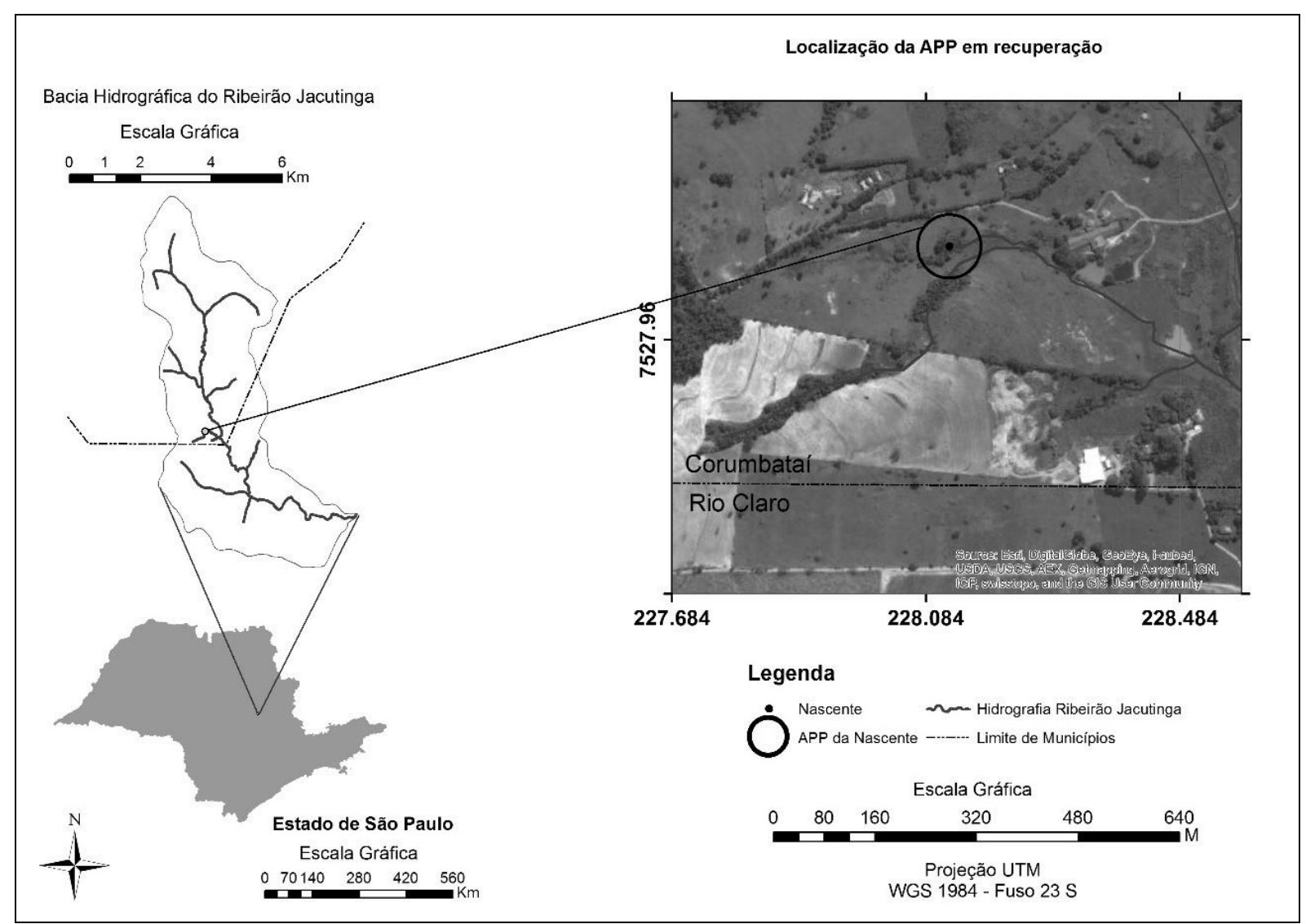

Figura 1. Localização da APP em recuperação.

(Organizada pelas autoras)

\section{MATERIAIS E MÉTODO}

Neste trabalho, para análise da viabilidade do uso da nucleação foram adotadas as seguintes etapas: $1^{\text {a }}$ ) caracterização ambiental da APP em estudo; 2 ${ }^{\mathrm{a}}$ ) monitoramento da regeneração natural desta APP; $3^{\mathrm{a}}$ ) análise dos fragmentos florestais remanescentes próximos a esta APP; $4^{\text {a }}$ ) implantação da técnica de nucleação escolhida; $5^{\mathrm{a}}$ ) monitoramento desta técnica de nucleação.

A etapa de caracterização ambiental da APP foi baseada no reconhecimento visual das características ambientais locais dos parâmetros indicados na Resolução SMA no 32, de 03 de abril de 2014 (SÃO PAULO, 2014b). A caracterização ambiental da APP iniciou com observação de imagens fornecidas pelo Software Google Earth (Google, 2014). O mesmo software foi utilizado em outro trabalho (Rodrigues \& Zaine, 2013), onde foi verificada a viabilidade da utilização destas imagens em estudos de planejamento ambiental. A partir destas imagens foram coletadas as coordenadas geográficas da nascente e com o auxílio de Global Positioning System (GPS) chegou-se a área. Com uma trena foi marcada a área da APP de nascente, com a extensão de raio de $50 \mathrm{~m}$ como exige a Lei $\mathrm{n}^{\circ} 12.651$, de 25 de maio de 2012 (BRASIL, 2012). Após delimitada a área, 
avaliou-se visualmente eventuais alterações, no relevo e na hidrografia, oriundas da extração de argila e de demais processos antrópicos em toda a APP. As atuais condições do solo quanto à presença de processos erosivos, também, foram analisadas visualmente. A cobertura vegetal da APP e a presença de regeneração natural, de banco de sementes, de plântulas e de plantas invasoras foram reconhecidas utilizando $\mathrm{o}$ método do caminhamento como proposto por Filgueiras et al. (1994). Para a classificação das espécies vegetais encontradas utilizou-se Lorenzi (2008a,b) e para classificar a qual bioma a área preservação pertence utilizou-se o Manual Técnico da Vegetação Brasileira do Instituto Brasileiro de Geografia e Estatística (IBGE, 2012). Estas análises contribuíram para determinar o grau de degradação do ecossistema local com base na Resolução CONAMA n ${ }^{\circ}$ 01, de 31 de janeiro de 1994 (BRASIL, 1994).

$\mathrm{Na}$ execução da $2^{\mathrm{a}}$ etapa, o acompanhamento do processo de regeneração da área estuda ocorreu após o isolamento dos agentes degradantes, com cerca de arame, permitindo apenas a passagem da fauna silvestre. Esta etapa consistiu em visitas mensais ao local nos meses chuvosos e visitas quinzenais nos meses de seca. Durante os meses de monitoramento, foram realizadas observações visuais no interior desta APP e em sua área de entorno, utilizando o método do caminhamento proposto por Filgueiras et al. (1994). Buscou-se com essas observações visuais, coletar dados relacionados ao processo de regeneração natural que está ocorrendo dentro e fora da APP.

Para a execução da $3^{\text {a }}$ etapa, a análise dos fragmentos florestais foi dividida em etapa de identificação e de caracterização. Esta análise é importante para viabilizar a implantação da nucleação, pois o fragmento florestal próximo deve apresentar características satisfatórias para fornecer material de empréstimo (serrapilheira, solo, galharia, sementes) à implantação da nucleação na área que se pretende recuperar (Martins, 2007). Na etapa de identificação da presença, de tamanho e da distância dos fragmentos próximos a APP em recuperação, foram utilizadas imagens fornecidas pelo Software Google Earth (Google, 2014) e ferramentas do software ArcGIS 10.2.1. (Esri, 2013). As ferramentas utilizadas foram Create
New Shapefile, Edit New Shapefile e Field Calculator. A partir destas imagens, foram coletadas as coordenadas geográficas destes fragmentos e com o auxílio de Global Positioning System (GPS) chegou-se à área para realizar a etapa de análise do grau de degradação dos fragmentos. A cobertura vegetal dos fragmentos, da presença de regeneração natural, de banco de sementes, de plântulas e de plantas invasoras foram caracterizadas utilizando o método do caminhamento proposto por Filgueiras et al. (1994). As espécies vegetais e o bioma ao qual os fragmentos pertencem foram caracterizados e classificados adotando as mesmas metodologias da etapa de caracterização da APP. Após identificada e classificada a vegetação dos fragmentos, a análise do estado de degradação dos fragmentos foi realizada embasada na Resolução CONAMA n ${ }^{\circ}$ 01, de 31 de janeiro de 1994 (BRASIL, 1994).

O período de implantação da técnica de nucleação, $4^{\text {a }}$ etapa, antecedeu o período chuvoso. O volume de material de empréstimo foi retirado do fragmento distante $800 \mathrm{~m}$ da área que está sendo recuperada e foi transportado com o auxílio de uma retroescavadeira. $\mathrm{O}$ material foi retirado apenas da camada superficial e fértil do solo (de 0,05 $\mathrm{m}$ a $0,10 \mathrm{~m}$ de profundidade) em pontos diversificados. O material foi coletado seguindo as orientações de Martins (2007). Os pontos de coleta foram aqueles que apresentaram características de possuir mais sementes dispersas no solo e na serrapilheira, visto que não foi possível identificar visualmente as sementes dispersas sobre a serrapilheira. Esta análise considerou a presença e diversidades de mudas em desenvolvimento e considerou também a diversidade das árvores maiores do local. Para o experimento, foi transplantado apenas um núcleo de solo e de serrapilheira na APP em recuperação. O tamanho do núcleo (Parcela 1) adotado neste trabalho foi de $0,50 \mathrm{~m}$ de profundidade com área de $1 \mathrm{~m}^{2}$. $\mathrm{O}$ solo depositado nesta parcela resultou da homogeneização das porções de solo coletadas nos distintos pontos da área de empréstimo. Por cima do solo, foi depositada a serrapilheira.

Para realizar a $5^{\text {a }}$ etapa, dentro da APP em recuperação, também foi demarcada uma segunda parcela (Parcela 2) que teve apenas o 
solo revolvido. Esta parcela apresenta o mesmo tamanho da Parcela 1, e está localizada próxima à Parcela 1. Durante os meses de visita de campo, foram coletados dados de desenvolvimento da técnica de nucleação. Esses dados são embasados em observações visuais do desencadeamento dos processos sucessionais ocorridos nas Parcelas 1 e 2. O acompanhamento dos processos sucessionais oriundos do uso da técnica de nucleação consistiu em visitas mensais as Parcelas nos meses chuvosos e visitas quinzenais nos meses de seca. Sendo que nos meses de seca, durante as visitas quinzenais, foi realizada a irrigação da parcela transplantada. A demarcação da Parcela 2, ocorre para comparar os diferentes processos suceccionais que ocorrem em área que recebe material de empréstimo, através da técnica de nucleação, com uma área que teve apenas o solo revolvido sem acréscimo de material de empréstimo. Todas as comparações eram feitas através de observações visuais.

\section{RESULTADOS}

A cobertura vegetal predominante na APP predominante é a Brachiaria sp. utilizada para pastagem. Dentro desta APP, ocorre a presença de um fragmento florestal remanescente (Fragmento 1) de vegetação de Floresta Estacional Semidecidual. O Fragmento 1 possui fisionomia florestal com a presença de estratos de diferentes alturas, com variações de espaçamentos. Neste fragmento, há uma pequena quantidade de trepadeiras, ocupando áreas com distribuição irregular na borda do fragmento. O estrato arbóreo do Fragmente 1 apresenta altura média de $7 \mathrm{~m}$, porém há árvores com até 9 e $12 \mathrm{~m}$ compondo o dossel. A camada de serrapilheira está presente em toda sua extensão, mas sua espessura é variável conforme a estrutura do fragmento. Esta APP, no passado, passou por processo de terraplanagem, o que descaracterizou os impactos visuais oriundos da atividade de extração de argila no relevo. Os impactos da mineração ainda perceptíveis são o assoreamento do leito do afluente do Ribeirão Jacutinga iniciado na nascente da APP e redução do volume hídrico do mesmo. Os processos erosivos da área de estudo são de baixa intensidade e não apresentam solo exposto. A forma de erosão predominante na área são sulcos formados pela compactação do solo devido ao pisoteio do gado. $\mathrm{Na}$ área, foram identificados, também, sulcos formados pela erosão hídrica intensificados pelo pisoteio do gado próximo à nascente.

Antes do isolamento da APP, a pastagem dentro e fora da APP não apresentava diferença quanto à altura da Brachiaria sp.. Além da presença da Brachiaria sp., era possível notar de ambos os lados do cercamento, logo após o isolamento, apenas o desenvolvimento de mudas de espécies invasoras. Durante os meses de monitoramento, foi possível notar diferença na altura da cobertura vegetal entre as áreas de pastagem dentro e fora da APP. $\mathrm{Na}$ área isolada, ou seja, dentro da APP, a Brachiaria sp. apresentava altura em torno de $25 \mathrm{~cm}$ e em alguns pontos foi possível observar mudas de provável nativas se desenvolvendo, além de espécies florescendo. Por sua vez, na área não isolada, não foram identificadas mudas de espécies diferentes das invasoras já identificadas durante a caracterização da área de estudo. Outra mudança percebida, na área dentro da APP, foi que a drenagem antes exposta, agora encontra-se toda coberta por vegetação. As alterações observadas sugerem que a APP está em processo de regeneração natural.

Além do Fragmento 1, foram observados outros quatros remanescentes florestais significativos (Figura 2), próximos à APP que está em recuperação. Juntos, estes fragmentos totalizam uma área de 6,69 ha. Todos os fragmentos florestais estudados são remanescentes de Floresta Estacional Semidecidual, de acordo com a classificação do Manual Técnico da Vegetação Brasileira (IBGE, 2012), com diferentes níveis de preservação. Estes fragmentos florestais fazem vizinhança com cultivos de eucalipto e de canade-açúcar, mineração de argila e área de pastagem, e não estão isolados da ação de agentes degradantes, como o gado, além de apresentarem indicativos de terem sido minerados, em função dos cortes no perfil do relevo. Todos os fragmentos identificados são de mata ciliar cujo corpo hídrico foi 
provavelmente assoreado o que pode justificar a

Jacutinga.

vazão intermitente destes afluentes do Ribeirão

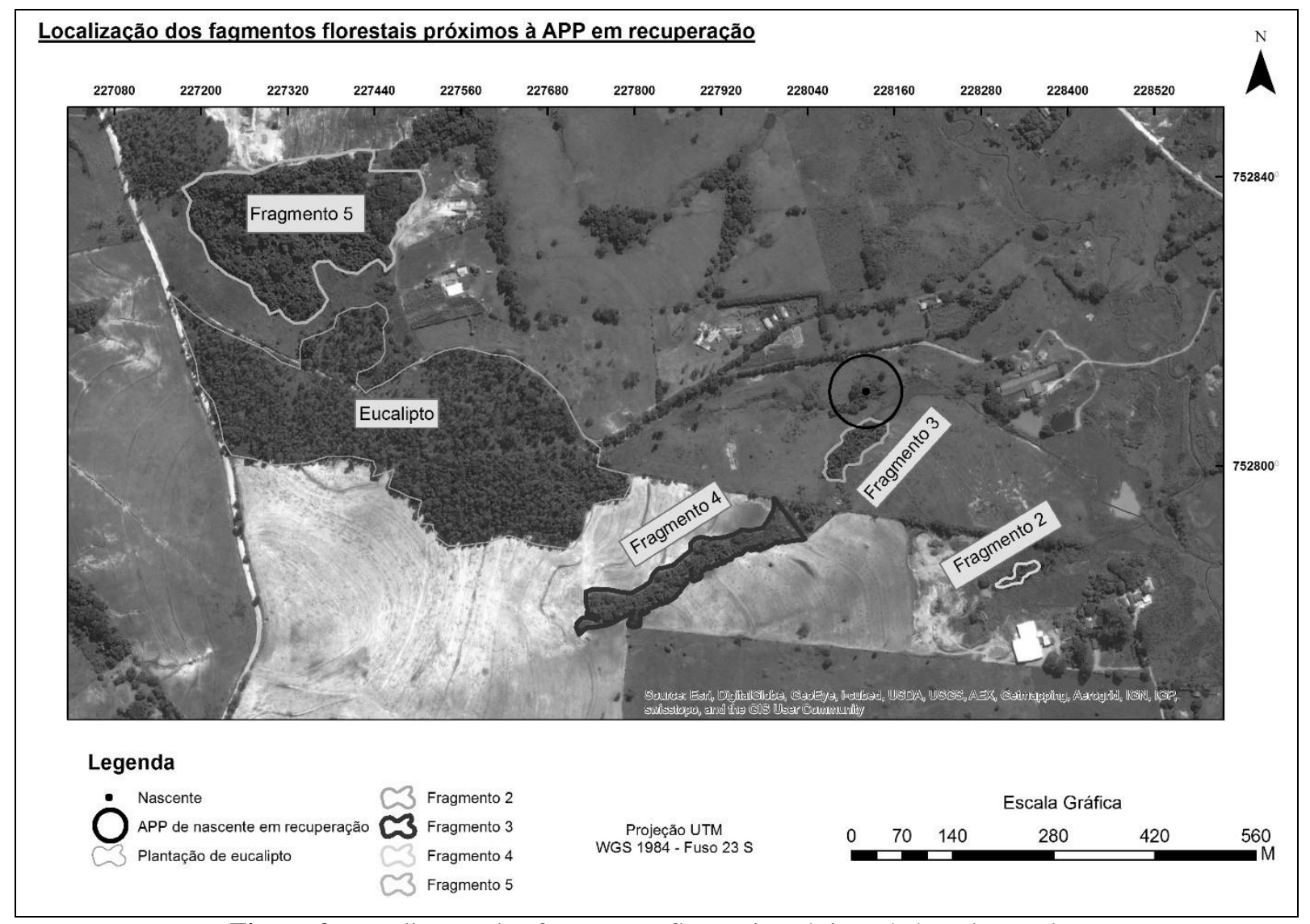

Figura 2. Localização dos fragmentos florestais próximos à área de estudo

(Organizada pelas autoras)

Os Fragmento 2, 3 e 4 apresentam formato alongado com inclinação topográfica variada com diferentes graus de degradação. Acreditase que a baixa diversidade de espécies dos Fragmentos 2, 3 e 4 esteja associada ao efeito de borda ao qual estes estão susceptíveis devido ao formato alongado dos mesmos. Próximo às extremidades dos fragmentos, o terreno é mais inclinado e no interior a inclinação passa despercebida. A espessura de serrapilheira e de solo nos Fragmento 2, 3 e 4 varia conforma a inclinação do terreno. Nas porções inclinadas do terreno, a espessura de serrapilheira e de solo é maior que nas partes mais planas do terreno.

O Fragmento 5 é enquadrado em estágio médio de regeneração segundo as premissas dispostas na Resolução CONAMA n ${ }^{\circ}$ 01, de 31 de janeiro de 1994 (BRASIL, 1994). A fisionomia é florestal com dossel em torno de 8 a $10 \mathrm{~m}$ de altura, com a presença de emergentes de até $20 \mathrm{~m}$ de altura. O chão é composto por serrapilheira contínua de espessura média no interior de toda a mancha de vegetação. Há presença de diversas espécies herbáceas e indivíduos jovens des espécies arbustivas e trepadeiras, bem como mudas de espécies arbóreas. As espécies de trepadeiras estão representadas, sobretudo por espécies lenhosas concentrada na borda do fragmento. O número de epífitas é baixo e há variação entre as espécies arbóreas verificadas no interior e na borda deste fragmento. Não há indícios de espécies exóticas se desenvolvendo no local, a exceção de Oececlades maculata, (orquídea africana) comumente naturalizada em vegetação nativa de Mata Atlântica.

$\mathrm{O}$ material de empréstimo para a implantação da técnica de nucleação escolhida (transposição de solo e serrapilheira) foi retirado do Fragmento 5. Durante a coleta, foi possível visualizar algumas sementes de espécies distintas. Formando a serrapilheira, foi observada uma variedade de matéria orgânica em decomposição, como raízes, folhas e gravetos, além de musgos. 
No mês de implantação da técnica, a camada de serrapilheira na Parcela 1 era de $25 \mathrm{~cm}$. Nos dois meses seguintes, a serrapilheira desta parcela sofreu decomposição, reduzindo sua espessura, respectivamente, para $5 \mathrm{~cm}$ e $1 \mathrm{~cm}$. Devido à mínima espessura da camada de serrapilheira, foi possível observar sementes e presença de olho de formigueiro. No terceiro mês, após três meses de chuva desde a implantação da técnica, germinaram as primeiras espécies na Parcela 1. No quarto mês, observou-se que as espécies que estavam germinando na parcela morreram e formou-se outro olho de formigueiro dentro desta parcela. Além de não ter ocorrido o desenvolvimento de nenhuma espécie vegetal, o solo movimentou- se. Neste mês, a frequência das chuvas reduziu e as visitas passaram a ser quinzenais, com irrigação desta parcela com água. Nas visitas de campos seguintes, a Parcela 1 não apresentou nenhuma alteração quanto à disposição do solo, nenhuma espécie germinando. A presença de formigas passou a ser constante, sendo que a cada visita, o olho do formigueiro estava em pontos distintos da Parcela 1. E durante as visitas, a cada monitoramento aumentava-se a visualização de sementes de diferentes espécies na parcela de solo e serrapilheira transplantada. Associa-se a possibilidade de visualização de maior diversidade de sementes com o fato de a redução do volume de serrapilheira permitir melhor visualização.

\section{DISCUSSÃO}

Depois de realizada a caracterização ambiental da APP e confirmada a ocorrência da regeneração natural na mesma, é possível concluir pelas premissas de Martins (2013) que a APP está passando pelo processo de regeneração natural após o isolamento dos agentes degradantes.

Para acelerar o processo de recuperação, este trabalho adotou o uso de nucleação como sugerem Yarranton \& Morrison (1974), Franks (2003), Reis et al. (2003), Bechara et al. (2007), Reis et al. (2010) e Martins (2012). Para adotar o uso das técnicas de nucleação, buscou-se fragmentos florestais próximo com características satisfatórias para empréstimo de material para a implantação dos núcleos, sendo este um dos pré-requisitos para o sucesso da implantação da nucleação e consequente recuperação da área degradada, assim como abordado em Martins (2013, 2014).

Dentre todos os fragmentos florestais identificados próximos à APP em recuperação, descartaram-se os Fragmentos 2, 3 e 4 para serem usados como fragmentos florestais de material de empréstimo, visto que estes não apresentavam volume de material de empréstimo suficiente para garantir seus fluxos energéticos. Nos Fragmentos 2, 3 e 4, nas partes inclinadas, onde há espessura significativa de serrapilhiera e de solo, não foram identificadas espécies férteis, ou seja, não ocorre indicativo de formação de banco de sementes nesta serrapilheira. Na parte plana, foram encontradas flores, o que seria um indicativo de formação de banco de sementes, contudo devido à pequena espessura da camada de serrapilheira e de solo, as sementes e flores que ali se depositam são carreadas juntas com a água da chuva, impossibilitando a formação de um banco de sementes.

A área, a localização, a presença intensa de muda e a maior variedade de espécies do Fragmento 5 foram fatores positivos para o uso deste fragmento como área de empréstimo de material. A retirada de material ocorreu em pontos diversos, dentro do fragmento 5 , de forma a proporcionar à área que recebeu o material transplantado uma grande variedade de sementes, assim como orienta Martins (2007).

Após caracterizado o Fragmento 5, estudou quais entre as técnicas de nucleação seriam as mais apropriadas para a recuperação da APP. Neste momento, foram descartadas a técnica de transposição de galharia e a técnica de chuva de semente. Estas técnicas foram descartadas, visto que o Fragmento 5 não apresentava material em volume suficiente para a implantação destas na APP. A técnica de implantação de poleiros seco e vivo, foi adotada indiretamente, uma vez que a fauna silvestre local pode utilizar as estacas do cercamento da APP, as árvores e as arvoretas como poleiros. Sendo assim, a única técnica de nucleação escolhida para ter monitorada sua viabilidade, foi a transposição de solo e serrapilheira, em 
função da presença intensa de muda e grande variedade de espécies do Fragmento 5.

Depois de implantada a técnica de nucleação, foi realizado o monitoramento por cinco meses. A maior dificuldade encontrada foi em manter uma umidade do solo ideal para o desenvolvimento das sementes na parcela implantada. Após períodos chuvosos, foi possível notar, na parcela implantada, o início de desenvolvimento de mudas, contudo estas mudas não vingaram nos meses seguintes. Associa-se o não desenvolvimento das mudas com a redução da umidade do solo. Acredita-se que um acompanhamento semanal, com irrigação frequente da Parcela 1, as mudas possam se desenvolver, visto que é possível identificar diversas sementes presentes na parcela transplantada. A partir do mês de fevereiro, presença de formigas na parcela foi constante. A decomposição da matéria orgânica da serrapilheira e a presença de formigas são indicativos de intensa atividade biológica na parcela transplantada.

Comparando a parcela implantada com a parcela que teve apenas o solo revolvido, percebe que as características físicas do solo são distintas. Enquanto o solo da parcela transplantada é solto e rico em matéria orgânica, o solo da outra parcela voltou a ficar compactado mesmo na ausência do pisoteio do gado. Enquanto na parcela transplantada é possível identificar diversidade de sementes e presença da microfauna, na parcela de solo revolvido não ocorre nem a presença de microfauna, como formigas. A comparação entre estas duas parcelas, confirma que o uso da nucleação, através da técnica de transposição de solo e serrapilheira, serve como "gatilho ecológico" para acelerar a regeneração natural de uma área degradada.

Comparando os processos sucessionais da regeneração natural que ocorreram dentro da APP isolada com os processos sucessionais que ocorreram na área de pastagem fora da APP, observou-se que os processos sucessionais da pastagem isolada, ou seja, lado de dentro da APP, estão ocorrendo mais rápido que os processos sucessionais da regeneração natural da área de pastagem fora da APP.

\section{CONCLUSÃO}

$O$ que se pode concluir em relação à viabilidade do uso da técnica de nucleação, até o momento, foi a formação de um banco de sementes implantado no núcleo transplantado com material de origem do fragmento florestal remanescente próximo (Fragmento 5). Além da formação do banco de sementes, a melhoria da qualidade física do solo do núcleo e a presença da microfauna na parcela observadas, pode favorecer o desencadeamento de processos sucessionais na APP. A ausência de mudas em desenvolvimento até o final deste trabalho, não inviabiliza o uso da técnica de nucleação na área em recuperação, isto porque, segundo Yarranton \& Morrison (1974), Franks (2003), Reis et al. (2003), Bechara et al. (2007), Reis et al. (2010) e Martins (2012), ao adotar as técnicas de nucleação trabalha-se com eventualidades e imprevisibilidades de tempo e espaço.

Justificada a viabilidade da técnica de nucleação, acredita-se que o projeto de recuperação da APP em estudo poderia ser elaborado com base na nucleação. A viabilidade é baseada na presença de fragmentos florestais remanescentes dentro da APP em recuperação e em suas proximidades, nas poucas evidências de processos erosivos e no desenvolvimento de mudas dentro da APP após o isolamento da mesma. Outro fator que favorece o uso da nucleação no projeto de recuperação da área, é que o fragmento florestal que forneceu o material de empréstimo também está localizado na propriedade do empreendedor.

A CETESB ao aceitar o projeto de recuperação da Área de Preservação Permanente baseado na nucleação pode estimular os proprietários rurais que necessitam licenciar seus empreendimentos a conservar os fragmentos florestais de suas propriedades. Ademais, o uso de nucleação torna o projeto de recuperação menos oneroso.

Para outras áreas que precisem ser recuperadas com características semelhantes à da APP estudada, características como fragmento florestal remanescente próximo e baixa evidências de processos erosivos, sugere- 
se que o projeto de recuperação da área degradada seja iniciado apenas com o monitoramento da regeneração natural, após o cercamento da área. Estudos, como os de Fadel et al. (2012) e o de Scalco (2012), comprovam que em determinadas regiões, mesmo com uma paisagem bastante fragmentada, é possível observar a regeneração natural ocorrendo em áreas degradadas. Caso os resultados do monitoramento da regeneração natural sejam positivos, projetos de recuperação das áreas degradadas apenas baseado na regeneração natural são indicados. E em casos de resultados negativos para o monitoramento da regeneração natural, aconselha-se a adoção de técnicas de recuperação de áreas degradadas mais elaboradas.

Conforme avançam os trabalhos relacionados a conservação do meio ambiente, é perceptível a importância de educar ambientalmente todos os responsáveis pela a alteração da paisagem em que vivem, ressaltando a necessidade de ocuparem de forma mais racional do espaço, respeitando as limitações impostas pelo meio ambiente. É fundamental no caso dos pequenos produtores de cerâmica vermelha, que os mesmos vejam nas iniciativas ambientais não somente a obrigação de estarem em conformidade com exigências dos órgãos governamentais, mas também a possibilidade de melhorarem suas produtividades a partir da utilização de técnicas sustentáveis de extração e produção. Técnicas estas que busquem priorizar a melhoria do ambiente de trabalho, da administração dos recursos naturais e da qualidade ambiental da propriedade rural.

Através deste projeto, os graduandos e pósgraduandos além de desenvolverem habilidades técnicas sob orientações dos docentes vinculados aos projetos, ficam mais próximos da sociedade e desenvolvem habilidades de comunicação com os proprietários rurais e com o órgão ambiental licenciador e fiscalizador. Projetos como estes, que estimulam a interação entre os alunos da universidade e os empreendedores, colocam os alunos mais próximos de problemas vivenciados pela sociedade e os estimulam no seu papel de cidadão no quesito de ajudar a sociedade através da ciência. O resultado é muitas vezes a humanificação dos profissionais que geralmente tiveram uma formação acadêmica exata rígida, além de ser uma oportunidade de troca de conhecimentos entre os cidadãos, o que resulta em avanços para o desenvolvimento da ciência e pesquisa no Brasil.

\section{AGRADECIMENTOS}

À FUNDUNESP (Fundação para o Desenvolvimento da Unesp) e ao CNPq (Conselho Nacional de Desenvolvimento Científico e Tecnológico) pelo apoio financeiro.

\section{REFERÊNCIAS BIBLIOGRÁFICAS}

1. BECHARA, F. C.; CAMPOS FILHO, E. M.; BARRETO, K. D.; GABRIEL, V. A.; ANTUNES, A. Z.; REIS, A. Unidades Demonstrativas de Restauração Ecológica através de Técnicas Nucleadoras de Biodiversidade. Revista Brasileira de Biociências, Porto Alegre, v. 5, supl. 1, p. 9-11, jul. 2007.

2. BRASIL. Conselho Nacional do Meio Ambiente. Resolução CONAMA no 1 , de 31 de janeiro de 1994. Diário Oficial [da] República Federativa do Brasil, Brasília, DF, 3fev. 1994. p. 1684-1685. Disponível em: < http://www.mma.gov.br/port/conama/legiabre.cfm?codle gi=142 >. Acesso em: 20 abr. 2014.

3. BRASIL. Departamento Nacional de Produção Mineral. Portaria $\mathrm{n}^{\circ}$ 237, de 18 de outubro de 2001. Diário Oficial [da] República Federativa do Brasil, Brasília, DF ,19 out. 2001. Disponível em:<http://www.diariodasleis.com.br/busca/exibelink.ph p?numlink=1-60-29-2001-10-18-237 >. Acesso em: 10 jun. 2015.

4. BRASIL. Lei $n^{\circ} 12.651$, de 25 de maio de 2012. Diário Oficial [da] República Federativa do Brasil, Brasília, DF, 28 maio 2012. Disponível em <http://www.planalto.gov.br/ccivil_03/_ato2011-

2014/2012/lei/112651.htm>. Acesso em: 06 jan. 2014.

5. DAITX, E. C. \& FERREIRA, G. C..Projeto Parceria - FUNDUNESP/SEBRAE-SP-Prefeitura Municipal de Rio Claro. Apoio técnico às atividades de extração de matéria-prima executadas pela indústria oleira da região de Rio Claro. Rio Claro, SP: IGCE/UNESP, 2006.

6. ESRI. ENVIRONMENTAL SYSTEM RESEARCH INSTITUTE. ARC/INFO. Version 10.2. 2013. DVD-ROM.

7. FADEL, N.; RAYMUNDO JR., O.; SAYEG, H. S. Caracterização e avaliação temporal de remanescentes 
florestais do município de Araras/São Paulo. HOLOS Environmental, Rio Claro, v. 12, n. 2, p. 215 - 224, 2012.

8. FERREIRA, G. C..Plano de Lavra Requerimento de Registro de Licença. DNPM Argila para Cerâmica Vermelha. Rio Claro, SP: IGCE/UNESP, 2007.

9. FERREIRA, G. C.; DAITX, E. C.; OLIVEIRA, C. C. de; LIMA P. R. de. Programa de apoio à legalização mineral de olarias da região de Rio Claro (SP). Revista Escola de Minas, Ouro Preto, v. 65, n. 1, p. 119-126, jan./mar. 2012.

10. FERREIRA, G. C.; SCALCO, J. P.; PIERONI, J. P. Programa de apoio à legalização mineral e ambiental de Olarias da região de Rio Claro. In: Congresso Paulista de Extensão Universitária, 3., 2015, Santo André. Anais...Santo André: Universidade Federal do ABC, 2015. p. 119-120.

11. FILQUEIRAS, T. S.; BROCHADO, A. L.; NOGUEIRA, P. E.; GUALA G. F. Caminhamento - Um método expedito para levantamentos florísticos qualitativos. Caderno de Geociências, Rio de Janeiro, n. 12, p. 39-43, out./dez. 1994.

12. FRANKS, S. J. Facilitation in multiple life-history stages: evidence for nucleated succession in coastal dunes. Plant Ecology, v. 168, n. 1, p. 1-11, ago. 2003.

13. GOOGLE. Google Earth website. Version 7.1.2.2041. 2013. Disponível em: < http://earth.google.com/ >. Acesso em: 02 set. 2014.

14. IBGE. Instituto Brasileiro de Geografia e Estatística. Manual Técnico da Vegetação Brasileira. 2. ed.Rio de Janeiro: IBGE, 2012. n. 1. 272p.

15. LEMOS, C. M. G. Recuperação de área de preservação permanente através da nucleação como subsídio à adequação legal da atividade de extração de argila em pequena propriedade. Rio Claro, SP: IGCE/UNESP, 2015. Originalmente apresentada como Dissertação de Mestrado em Geociências e Meio Ambiente, Universidade Estadual Paulista, 2015.

16. LORENZI, H. Árvore Brasileiras: manual de identificação e cultivo de plantas arbóreas nativas do Brasil. 5.ed. Nova Odessa, SP: Instituto Plantarum, 2008a. v.1.

17. LORENZI, H. Plantas daninhas do Brasil: terrestres, aquáticas, parasitas e tóxicas. 3. ed. Nova Odessa, SP: Instituto Plantarum,2008b. 672p.

18. MARTINS, S.V. Recuperação de matas ciliares. 2. ed. Viçosa, MG: Aprenda Fácil Editora, 2007. 225 p.

19. MARTINS, S.V. Restauração ecológica de ecossistemas degradados. 1. ed. Viçosa, MG: Aprenda Fácil Editora, 2012. 293 p.

20. MARTINS, S.V. Recuperação de áreas degradadas: como recuperar áreas de preservação permanente, voçorocas, taludes, rodoviários e áreas de mineração. 3 ed. Viçosa, MG: Aprenda Fácil Editora, 2013.

21. MARTINS, S.V. Técnicas e práticas alternativas para restauração.Foz do Iguaçu. 2014. Mini-curso da Sociedade Brasileira de Recuperação de Áreas Degradadas.

22. REIS, A.; BECHARA, F.C.; ESPINDOLA, M.B.; VIEIRA, N.K.; SOUZA, L.L. Restauração de áreas degradadas: a nucleação como base para incrementar os processos sucessionais. Natureza \& Conservação, São Carlos, v. 1, n. 1, p. 28-36, abr. 2003.

23. REIS, A.; BECHARA, F. C.; TRES, D. R. Nucleation in tropical ecological restoration. ScientiaAgrícola(USP. Impresso), Piracicaba, v. 67, n. 2, p. 244-250, mar./abr. 2010.

24. RODRIGUES, F. H. \& ZAINE, J. E. Mapeamento Geológico-Geotécnico da Estrada de Castelhanos, Ilhabela (SP). Revista Brasileira de Geologia de Engenharia e Ambiental (RBGEA),São Paulo,v. 3, p. 159-172,2013.

25. SÃO PAULO (Estado). Decreto no 20.960, de 8 de junho de 1983. Declara área de proteção ambiental a regiões situadas em diversos municípios, dentre os quais Corumbataí, Botucatu e Tejupá. Diário Oficial [do] Estado de São Paulo, São Paulo, v. 93, n. 107, 1983.Disponível

em:<http://dobuscadireta.imprensaoficial.com.br/default. aspx ?DataPublicacao $=19830609 \&$ Caderno $=$ DOE -

I\&NumeroPagina=1 >. Acesso em: 10 jun. 2014.

26. SÃO PAULO (Estado). Companhia Ambiental do Estado de São Paulo. Decisão de Diretoria $n^{\circ}$ 025/2014/C/I, de 29 janeiro de 2014. Diário Oficial [do] Estado de São Paulo, São Paulo,n. 124 (20), p. 86 - 87, jan. 2014a. Disponível em: <http://www.cetesb.sp.gov.br/wp-

content/uploads/sites/11/2013/11/DD_025_2014_C_I_pa g_86.pdf >. Acesso em: $19 \mathrm{dez} .2014$.

27. SÃO PAULO(Estado). Secretaria de Estado do Meio Ambiente. Resolução SMA No 32, de 03 de abril de 2014. Estabelece as orientações, diretrizes e critérios sobre restauração ecológica no Estado de São Paulo, e dá providências correlatas. Diário Oficial [do] Estado de São Paulo, São Paulo, n. 65, sessão 1, p. 36 - 37, 05 abr. 2014b. Disponível

em:

<ftp://ftp.saude.sp.gov.br/ftpsessp/bibliote/informe_eletr onico/2014/iels.abr.14/Iels66/E_RS-SMA-

32_030414.pdf >. Acesso em: 19 ago 2014.

28. SCALCO, J. P. Caracterização dos impactos ambientais da indústria oleira e mineração na subbacia do Ribeirão Jacutinga - Municípios de Rio Claro e Corumbataí (SP). Rio Claro, SP: IGCE/UNESP, 2012. Originalmente apresentada como Dissertação de Mestrado em Geociências e Meio Ambiente, Universidade Estadual Paulista, 2012.

29. SCALCO, J. P. \& FERREIRA, G. C. Impactos ambientais da mineração de argila para cerâmica vermelha na sub-bacia do Ribeirão Jacutinga - Rio Claro e Corumbataí (SP). Geociências (São Paulo. Online), Rio Claro, v. 32, n. 4, p. 760-769,2013.

30. SCALCO, J. P.; LEMOS, C. M. G.; FERREIRA, G. C. Caracterização dos impactos ambientais de longo prazo oriundos da extração de argila em pequenas propriedades. In: Congresso brasileiro de avaliação de impacto, 2., 2014, Ouro Preto. Anais...Ouro Preto: Associação Brasileira de Avaliação de Impacto, 2014. p. 195-200. PEN-DRIVE.

31. VALENTE, R.O.A. Análise da Estrutura da Paisagem na Bacia do Rio Corumbataí. Piracicaba, SP: ESALQ/USP, 2001. Originalmente apresentada como Dissertação de Mestrado, Universidade de São Paulo, 2001 
32. YARRANTON, G. A. \& MORRISON, R. G.

Spatial dynamics of a primary succession: nucleation.

Journal of Ecology, Sheffield, v. 62, n. 2, p. 417-428, 1974.

Manuscrito recebido em: 14 de Abril de 2016 Revisado e Aceito em: 19 de Outubro de 2016 